\title{
Wave climate of the Adriatic Sea: a future scenario simulation
}

\author{
A. Benetazzo ${ }^{1}$, F. Fedele ${ }^{2}$, S. Carniel ${ }^{1}$, A. Ricchi ${ }^{3}$, E. Bucchignani ${ }^{4}$, and M. Sclavo ${ }^{1}$ \\ ${ }^{1}$ Institute of Marine Science, National Research Council (CNR-ISMAR), Venice, Italy \\ ${ }^{2}$ School of Civil and Environmental Engineering and School of Computer and Electrical Engineering, Georgia Institute of \\ Technology, Atlanta, Georgia, USA \\ ${ }^{3}$ University of Naples Parthenope, Naples, Italy \\ ${ }^{4}$ Italian Aerospace Research Centre (CIRA),Capua, Italy
}

Correspondence to: A. Benetazzo (alvise.benetazzo@ve.ismar.cnr.it)

Received: 14 December 2011 - Revised: 3 May 2012 - Accepted: 7 May 2012 - Published: 26 June 2012

\begin{abstract}
We present a study on expected wind wave severity changes in the Adriatic Sea for the period 2070-2099 and their impact on extremes. To do so, the phase-averaged spectral wave model SWAN is forced using wind fields computed by the high-resolution regional climate model COSMOCLM, the climate version of the COSMO meteorological model downscaled from a global climate model running under the IPCC-A1B emission scenario. Namely, the adopted wind fields are given with a horizontal resolution of $14 \mathrm{~km}$ and 40 vertical levels, and they are prepared by the Italian Aerospace Research Centre (CIRA). Firstly, in order to infer the wave model accuracy in predicting seasonal variability and extreme events, SWAN results are validated against a control simulation, which covers the period 1965-1994. In particular, numerical predictions of the significant wave height $H_{\mathrm{s}}$ are compared against available in-situ data. Further, a statistical analysis is carried out to estimate changes on wave storms and extremes during the simulated periods (control and future scenario simulations). In particular, the generalized Pareto distribution is used to predict changes of storm peak $H_{\mathrm{s}}$ for frequent and rare storms in the Adriatic Sea. Finally, Borgman's theory is applied to estimate the spatial pattern of the expected maximum wave height $H_{\max }$ during a storm, both for the present climate and that of the future scenario. Results show a future wave climate in the Adriatic Sea milder than the present climate, even though increases of wave severity can occur locally.
\end{abstract}

\section{Introduction}

The distributions and intensity of wind fields over the Mediterranean Sea (Fig. 1) are expected to change during the 21st century planning horizon, as a result of the anthropogenic climate change due to the enhanced greenhouse effect (IPCC, 2007). Estimation of wind changes (e.g., Rockel and Woth, 2007) is fundamental, since wind forcing plays a key role in controlling several aspects of the ocean dynamics. In the Adriatic Sea (located in the northeastern sector of the Mediterranean Sea; see Fig. 1), the most visible and impacting results are related to flooding or high wave conditions, coastal vulnerability and erosion processes (Carniel et al., 2011). In addition to this, dominant winds play a major role in triggering the associated surface stresses, which affect the water circulation (see, for example, Carniel et al., 2009). They also modify the heat budget by inducing significant water cooling episodes and triggering the dense shelf water formation episodes (see Supic and Vilibic, 2005; Carniel et al., 2011). Dominant winds are also responsible for establishing a vertical mixing regime that has important consequences for the distribution of nutrients, sediments and plankton (Boldrin et al., 2009).

In this context, since sea waves govern most of the dynamics of both offshore and coastal processes, there is a need to determine the extent to which climate change could affect the frequency and magnitude of extreme events. Thus, the prediction of wave state changes is of crucial importance to assist coastal decision-makers with climate adaptation, and for assessing the risk level in marine structure design and for the operation of offshore facilities. 


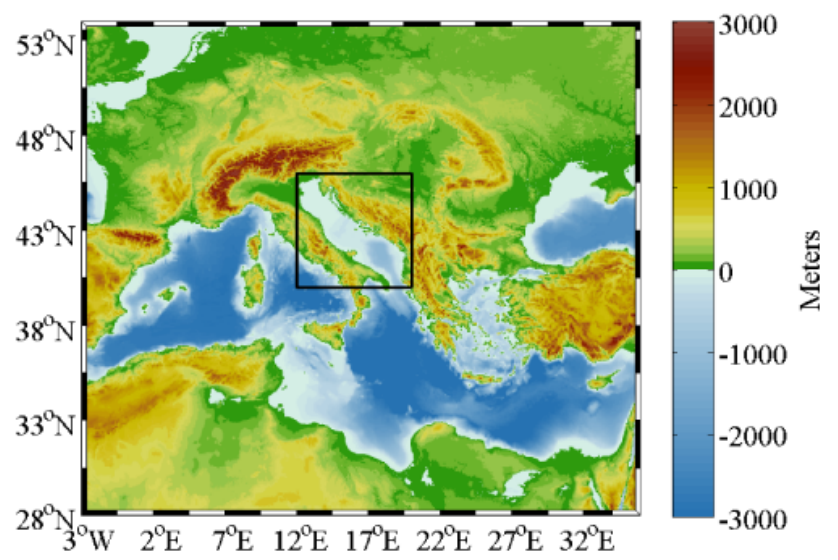

Fig. 1. Orography and bathymetry of the Mediterranean region. The Adriatic Sea area (delimited by a square) extends along the NW-SE direction from $40^{\circ}$ to $46^{\circ}$ North, with length of about $750 \mathrm{~km}$, and an average width of about $150 \mathrm{~km}$.

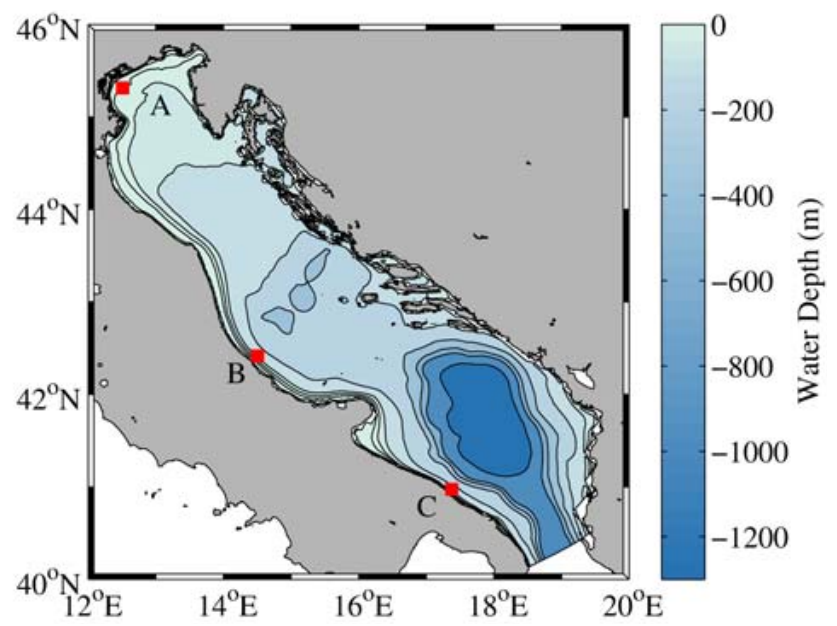

Fig. 2. Map of the Adriatic Sea bathymetry used by the SWAN model. The three markers show the locations used for wave measurements. The northern ISMAR-CNR (A) platform, and the central and southern Ortona (B) and Monopoli (C) buoys, respectively.

Indeed, in a risk-based approach the long-term wave state is defined by interpolating historical storm data in order to infer extreme value statistics. In such analyses, an underlying assumption is that sea states have the same statistical distribution, i.e. the climate conditions are stationary. This hypothesis allows estimating a design wave (e.g., the 100-yr return period wave height), extrapolating the available present data. Obviously, estimates of extremes depend on the accuracy and length of the observational data.

However, statistical approaches based on the assumption of stationarity would lead to invalid conclusions in the case of climate change: in this case, the extreme value statistics must be corrected to account for expected variations. To this end, the typical methodology, adopted to correct the present wave climate, is based on shifting the wave height distribution by a constant value, in order to account for the estimated future increase (Bitner-Gregersen and Eide, 2011, and references therein). This is, though, a simplification that assumes a notion of similarity between the extreme value distributions of both present and future data.

In terms of sea wave projected changes, Lionello et al. (2012) have recently shown how feasible is estimating the sea severity from future scenario simulations using regional climate model fields without the need of a statistical downscaling (as it was previously done in Lionello et al., 2003) nor the need to tune the wind fields magnitude to compensate for speed underestimation (Lionello et al., 2008). For example, Lionello et al. (2012) used the wave model WAM (WAve prediction Model) to investigate extreme wind wave and storm surge in the northern Adriatic Sea. WAM was set at a lat-long resolution of $0.25^{\circ}(\approx 25 \mathrm{~km})$ and forced by wind fields computed by RegCM (Pal et al., 2000$)$ at $0.60^{\circ}(\approx 60 \mathrm{~km})$ resolution, under A2 medium-high emission and $\mathrm{B} 2$ medium-low emission scenarios (see IPCC, 2000).

Along this line of thought, and in accordance with the model resolutions suggested by Lionello et al. (2012), the present paper aims at quantifying the changes of waves and their extremes in the Adriatic Sea (see Figs. 1-2), comparing the present conditions with those expected in the period 2070-2099 under the A1B medium emissions scenario hypothesis. The A1B scenario is the result of a balance of all energy sources, and it provides a mid-line scenario for carbon dioxide output and economic growth (IPCC, 2000, 2007). The analysis is performed using the SWAN (Simulating WAves Nearshore) wave model at a lat-long resolution of $0.08^{\circ}(\approx 8 \mathrm{~km})$, using winds fields produced at $0.14^{\circ}$ $(\approx 14 \mathrm{~km})$ resolution. These are provided by the climate version of the COSMO (COnsortium for Small-scale Modeling) model, forced by the global climate model CMCC-MED, with atmospheric model component provided by ECHAM5 with a T159 horizontal resolution, corresponding to a Gaussian grid of about $0.75^{\circ} \times 0.75^{\circ}$ (horizontal resolution of approximately $80 \mathrm{~km}$ ).

We point out that the case study investigated in this paper is a challenging test. Indeed, wind wave storms are rather frequent in the Adriatic Sea (see, for example, Lionello et al., 2012; Bignami et al., 2007; Sclavo et al., 1996). As an elongated semi-enclosed basin cast in the Mediterranean region (see Fig. 1), the Adriatic Sea extends mostly in the NWSE direction, from the shallow Gulf of Venice to the Strait of Otranto, where the bathymetry is strongly marked by a deep pit (Fig. 2). The most frequent winds blowing on the Adriatic Sea are the so-called Bora and Sirocco (Bignami et al., 2007), which cause high waves in the Adriatic Sea, although Bora waves are generally fetch-limited. In particular, Bora is a north-eastern, dry and cold wind, usually channelled through the Dinaric Alps and regarded as one of the cold air outbreak (CAO) processes, while Sirocco is a warmer and humid wind that blows from the E-SE direction. It typically 
occurs during the spring-fall period of the year, and it is generally less intense, warmer and wetter than Bora. Contrary to Bora, Sirocco is not fetch limited and therefore characterized by a progressive growth; although Bora winds can attain very high speed suddenly, Sirocco can grow slowly, reaching the highest speeds in the eastern Adriatic regions, and generally it decreases while proceeding to the western coasts, as pointed out by Signell et al. (2005). They have also shown how the resolution adopted by numerical weather prediction (NWP) systems is crucial for reproducing accurately dominant and transient winds in the Adriatic region, implicitly suggesting, among other characteristics, that numerical tools with horizontal grid size smaller than $20 \mathrm{~km}$ can significantly improve the accuracy of meteorological forcing for wave numerical models.

This paper is organized as follows. We first provide an overview of the regional climate simulations provided by the COSMO-CLM model. Then, we present the approach for wave numerical modeling in the Adriatic Sea and the statistical analysis of extreme events. The wave model results are then presented, comparing SWAN outputs to data available at the ISMAR-CNR oceanographic tower and from the directional buoys of the Italian national wave metric network managed by the Italian institute ISPRA. In particular, we consider the two buoys moored off the coast of Ortona and Monopoli, respectively (see Fig. 2). Then, the expected future variations of sea wave storms and extremes in the Adriatic Sea are presented. Finally, some conclusions are drawn and suggestions for future studies are discussed.

\section{Numerical models and methods}

\subsection{Meteorological COSMO-CLM model}

One of the procedures to assess the climate scenario in the present century consists of projected climatological forcing evaluated by means of global circulation models (GCM). GCM are fundamental to understand the climate and the consequences of its changes. They are, however, generally unsuitable for simulations on semi-enclosed basins, being characterized by resolutions around or coarser than $100 \mathrm{~km}$. These resolutions are too poor for impact studies, since many important phenomena occur at spatial scales of few tens of $\mathrm{km}$. In this context, the dynamical downscaling method (May and Roeckner, 2001) can be used to drive regional climate models (RCM), with boundary conditions provided by a GCM. Indeed, the usage of a RCM with a horizontal resolution of about $15 \mathrm{~km}$ can be a useful tool for the description of the climate variability on local scales, where the wind fields are highly structured.

In the present work, the climate model simulations are performed with the COSMO-CLM model (Rockel et al., 2008), the climate version of the COSMO model (see Steppeler et al., 2003 and http://www.cosmo-model.org), the opera- tional non-hydrostatic mesoscale weather forecast model developed by the German Weather Service. Successively, the model has been updated by the CLM-Community for climatic applications. The updates of its dynamical and physical packages empowered applications at cloud resolving scales. Indeed, the model can be used at high spatial resolutions, so that the orography is better described than that in global models, where the over/underestimation of valley/mountain heights yields errors in orographic winds, which strongly depend upon the terrain height. The mathematical formulation of COSMO-CLM is based on the Navier-Stokes equations for a compressible flow. The atmosphere is treated as a multicomponent fluid (made up of dry air, water vapor, liquid and solid water), for which the perfect gas equation holds and is subject to gravity and Coriolis forces. The parameterization settings include a Tiedtke convection scheme with a moisture convergence closure, a turbulence scheme with prognostic turbulent kinetic energy (TKE) and a Kessler scheme for grid-scale precipitation, which treats cloud ice diagnostically (for further details see Bucchignani et al., 2011).

The numerical experiment presented in this paper covers the domain $2-20^{\circ} \mathrm{E}$ and $39-52^{\circ} \mathrm{N}$, which has an extension of $1968 \times 1326 \mathrm{~km}^{2}$. For the analysis, we use the COSMOCLM model (Bucchignani et al., 2011) running at the Italian Aerospace Research Centre (CIRA) with a spatial resolution of approximately $14 \mathrm{~km}, 40$ vertical levels, and output every $6 \mathrm{~h}$ (C14E5 dataset). The simulation is carried out with boundary conditions provided by the global climate model CMCC-MED: it is a coupled atmosphere-ocean general circulation model, whose atmospheric model component is ECHAM5 in the T159 version, corresponding to a Gaussian grid with horizontal resolution of approximately $80 \mathrm{~km}$ and 6-h time resolution. Two 30-yr long periods covering the years 1965-1994 (control run, CTR) and 2070-2099 (future scenario, A1B) are extracted from the whole simulation that lasted from 1965 to 2099.

The adopted COSMO-CLM wind products were analyzed and assessed in the work of Bellafiore et al. (2012), where wind fields resulting from different regional climate models were compared versus observations collected at four different wind stations in the Adriatic Sea area. The results presented showed that C14E5 dataset was the best performing among five different datasets in reproducing the mean and extreme wind conditions in the Adriatic Sea, even if the tendency to underestimate Bora winds was shown.

\subsection{Wave SWAN model}

The sea surface ( $10 \mathrm{~m}$ height) wind fields obtained from the COSMO-CLM simulations are used to force a wave model in order to obtain the corresponding surface wave pattern. Two different 30-yr-long runs are carried out, representing the present wave climate (CTR run, period 1964-1995) and the expected future scenario (A1B run, period 2070-2099). 
The Adriatic Sea wind wave simulations are carried out using the SWAN (Simulating WAves Nearshore) model. SWAN is a third-generation wave model that computes random, short-crested wind-generated waves in offshore and coastal regions (see Booij et al., 1999). The model describes the generation, evolution and dissipation of the wave action variance density spectrum $E(\omega, \theta), \omega$ being the wave angular frequency, and $\theta$ as the wave direction. SWAN solves a radiative time-dependent transport equation in $E(\omega, \theta)$, accounting for the wind input, the wave-wave interactions, and the dissipation terms both in deep and shallow waters. Given $E(\omega$, $\theta$ ), various wave parameters can be estimated at any point of the computational domain. Typical output fields are the significant wave height, hereafter denoted as $H_{\mathrm{s}}$, the peak and mean wave periods, and the direction of mean wave propagation. In our simulations for the whole Adriatic Sea, the wave action is discretized with 36 equally spaced directions and 24 frequencies, $f$, geometrically distributed, such that $f_{n}=f_{n+1} / 1.1$, with $f_{1}=0.05 \mathrm{~Hz}$. SWAN is run on a computational grid with an average latitude-longitude grid step of $1 / 13^{\circ}$. On the southeastern boundary (Strait of Otranto) incoming waves are set to zero for simplicity, because the region within $100-200 \mathrm{~km}$ of the boundary is not of primary interest.

The SWAN model is run in non-stationary mode (i.e., the $E(\omega, \theta)$ variable evolves with time), with the outputs saved with a 3-h step. For the future scenario simulations, the Adriatic Sea bathymetry is corrected in accordance with the A1B mid-range emission scenario that predicts an average sea level rise of $0.35 \mathrm{~m}$ at the end of the $21 \mathrm{st}$ century (IPPC, 2007 and references therein). Examples of successful applications of SWAN model for the Adriatic Sea are given by Dykes et al. (2009) and Signell et al. (2005).

\subsection{Wave extremes}

At any point of the computational grid, SWAN yields the time evolution of the significant wave height $H_{\mathrm{s}}(t)$ for the given simulation time as a sequence of three hourly sea states. Wave extremes can then be investigated in accordance with the peaks over threshold (POT) approach, which is a good compromise between the initial distribution and the annual maximum method (Vinoth and Young, 2011). To do so, the first step involves the definition of sea wave storms in the $H_{\mathrm{S}}$ time sequence of sea states. Following Boccotti (2000), a storm is defined as a sequence of consecutive $H_{\mathrm{s}}(t)$, in which $H_{\mathrm{S}}$ exceeds a given threshold, fixed equal to 1.5 times the average value of $H_{\mathrm{s}}(t)$. To ensure stochastic independency, storms with successive peaks that occur within an interval less than $10 \mathrm{~h}$ are aggregated together, and sea storms lingering above the prescribed threshold for a time interval less than $12 \mathrm{~h}$ are discarded. Finally, the peak value of $H_{\mathrm{s}}$ for each storm is defined as an extreme and denoted as $H_{\mathrm{s} \text {,peak }}$.

We then rank the $n$ observed extremes into the order statistics: $y_{1}>y_{2}>\ldots \ldots y_{n}$, where $y=H_{\text {s,peak }}$, assuming their independence and that they are distributed according to the same parent distribution. Under these assumptions, the mean value $E$ and standard deviation $\sigma$, the estimate of the exceedance probability $\operatorname{Pr}\left\{y>y_{j}\right\}$ for the $j^{\text {th }}$ largest value $y_{j}$, are given, respectively, by (see, for example, Tayfun and Fedele, 2007):

$E=\frac{j}{n+1} ; \sigma=\frac{1}{n+1} \sqrt{\frac{j(n-j+1)}{n+2}}$.

Here, $n$ is the number of observations (i.e., the storms) and $j$ is the position of the observations in the ordered data. Note that $E$ is an indicator of the average return period, $R\left(H_{\mathrm{s} \text {,peak }}>y\right)$, between two successive storms above the threshold $y$. Indeed, if $N$ is the number of years covered by the analysis, $R=N /(n E)$, and the associated confidence intervals are $R^{ \pm}=N /(n(E \pm \sigma))$. Note that the variation coefficient of $E$, viz. $E / \sigma \approx \sqrt{1 / j}$, indicates that return levels of high extremes (corresponding to small value of the variable $j$ ) are estimated with an uncertainty of the same order of magnitude of that of the level itself.

In accordance with Coles (2001), the observed POT-based empirical extreme distribution follows the generalized Pareto distribution (GPD; see, for example, Brodtkorb et al., 2000), whose cumulative probability function is given by

$F\left(H_{\mathrm{s}, \text { peak }}\right)=1-\left[1+k\left(\frac{H_{\mathrm{s}, \text { peak }}-\mu}{\sigma}\right)\right]^{-1 / k}$

where $\mu, \sigma$, and $k$ are the GPD parameters estimated by means of the method of maximum product of spacings (Shao and Hahn, 1999).

To account for the variability of sea states during a storm, we also consider the expected maximum individual wave height, $H_{\max }$, in a sea storm with a given history, $H_{\mathrm{s}}(t \epsilon$ $\left.\left[t^{*}, t^{*}+D\right]\right)$, where $t^{*}$ is the time at which the storm begins, and $D$ is the storm duration. For instance, following Borgman (1973) we can express the expected maximum wave height, $H_{\max }$, at a given location as

$H_{\max }=\int_{0}^{\infty} 1-\exp \left\{\int_{0}^{D} \frac{1}{T\left(H_{S}(t)\right)} \operatorname{In}\left[1-P\left(z \mid H=H_{s}(t)\right)\right] d t\right\} d H$.

Here, given a state with intensity $H_{\mathrm{S}}, T$ is the associated mean wave period and $P\left(z \mid H_{s}\right)$ is the exceedance probability of the wave height $z$, given by the Rayleigh and Tayfun distributions for linear and nonlinear waves, respectively (see, for example, Tayfun and Fedele, 2007). The main assumption of the Borgman's model (4) is that the sequences of wave maxima of each sea state composing the storm are stochastic independent (see Borgman, 1973; see also Boccotti, 2000). The validation of such assumptions requires continuous measurements of the wave surface displacements at the buoy location during the storm. These displacements unfortunately are not available for the buoys of Ortona and Monopoli. However, 
during the WAVEMOD project (Prevosto et al., 2000), continuous data recordings were available and made it possible to really check the dependency of maxima in adjacent wave records of duration $30 \mathrm{~min}$, and no dependency on a statistically significant level was revealed. The Borgman model has been also validated numerically via Monte Carlo simulations (Forristall, 2008). Note that Eq. (4) accounts for storm growth and decay, and it is a key element in the long-term analysis of extreme waves (see, for example, WMO, 1998; Boccotti, 2000; Fedele and Arena, 2010; Fedele, 2012).

\section{Wave climate model validation}

The simulated climatic scenario is validated by comparing the CTR run statistics with observations. The local wave climate is inferred from buoy data recorded by the Italian national wave network at two different locations in the Adriatic Sea (see Fig. 2): Ortona $\left(42^{\circ} 24^{\prime} 54^{\prime \prime} \mathrm{N}\right.$, $\left.14^{\circ} 30^{\prime} 21^{\prime \prime} \mathrm{E}\right)$ and Monopoli $\left(40^{\circ} 58^{\prime} 30^{\prime \prime} \mathrm{N}, 17^{\circ} 22^{\prime} 36^{\prime \prime} \mathrm{E}\right)$. The buoys are managed by the Italian institute ISPRA (see http://www.idromare.it/index.php). We also consider data available at the ISMAR-CNR platform in the northern Adriatic $\left(45^{\circ} 18^{\prime} 83^{\prime \prime} \mathrm{N}, 12^{\circ} 30^{\prime} 53^{\prime \prime} \mathrm{E}\right)$. Both buoys are moored at a sea depth of approximately $100 \mathrm{~m}$, while the platform is located in a $16 \mathrm{~m}$ water depth. Observed buoy data are available for the period 1 July 1989 - 24 March 2008, while wave heights were recorded at the platform during the period 1 January 2004 - 31 August 2011 using an ultrasonic probe. Observations are sub-sampled every $3 \mathrm{~h}$ using averages to allow a direct comparison with model outputs. For comparison, sequences of sea states in the model grid position closest to the expected buoy and platform locations are extracted from the CTR and A1B runs.

Figure 3 presents the annual cycle of the monthly 95th percentile $H_{\mathrm{S}}$ computed by the SWAN model (CTR run: blue line) and derived from wave measurements (black line) at the two buoys of Ortona and Monopoli and at the ISMAR-CNR platform. For the future reference, A1B run data are plotted in the same figure as a dashed red line. In agreement with other recent studies (Lionello et al., 2003, 2008), no systematic wave height underestimation appears evident, and this used to plague runs based on global climatological models. More specifically, even though model results and observations cannot be fully reconciled at the ISMAR-CNR platform in winter and spring, modeled and observed data reproduce the annual variability of wave cycles. A1B run results show a reduction of wave heights in winter, even if the changes lie in the inter-annual variability of the wave values.

In terms of extreme values of modeled (CTR and A1B runs) and measured data, the GPD is fitted to the $H_{\mathrm{s}}$ storm peaks. To be statistically significant, the extreme event analysis approach requires a large number of events to be considered. Because of this, for wave model validation, this analysis is applied to the 19-yr long buoy datasets (therefore the
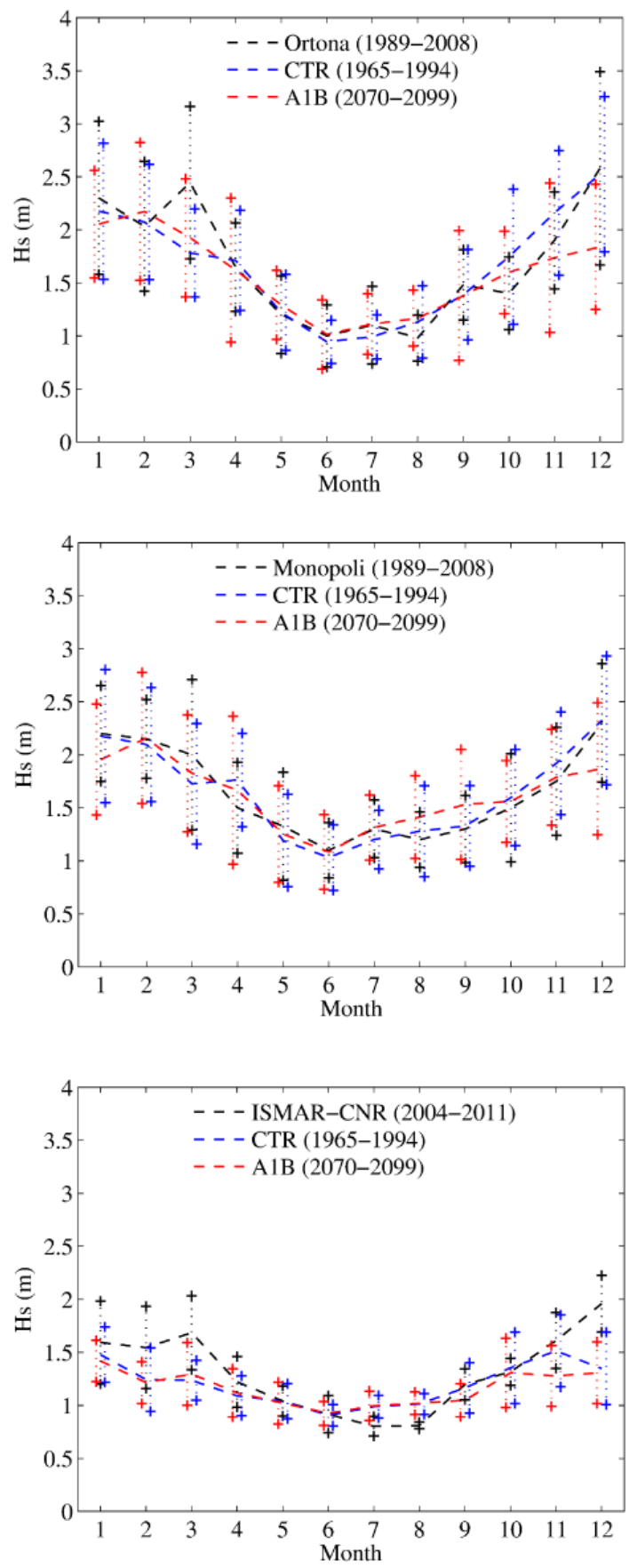

Fig. 3. Monthly 95 th percentile $H_{\mathrm{S}}$ comparison between modeled (blue: CTR run; red: A1B run) and observed data (black) for Ortona buoy (top), Monopoli buoy (center), and ISMAR-CNR platform (bottom). The vertical bars show the standard deviations of every entire dataset (for graphic purposes, CTR and A1B run data are slightly horizontally shifted).

ISMAR-CNR data are not used in this analysis, since they are available for a much shorter period, viz. 2004-2011). For example, $H_{\mathrm{s} \text {,peak }}$ return periods at the Ortona buoy are shown in Fig. 4, together with the associated confidence intervals. 


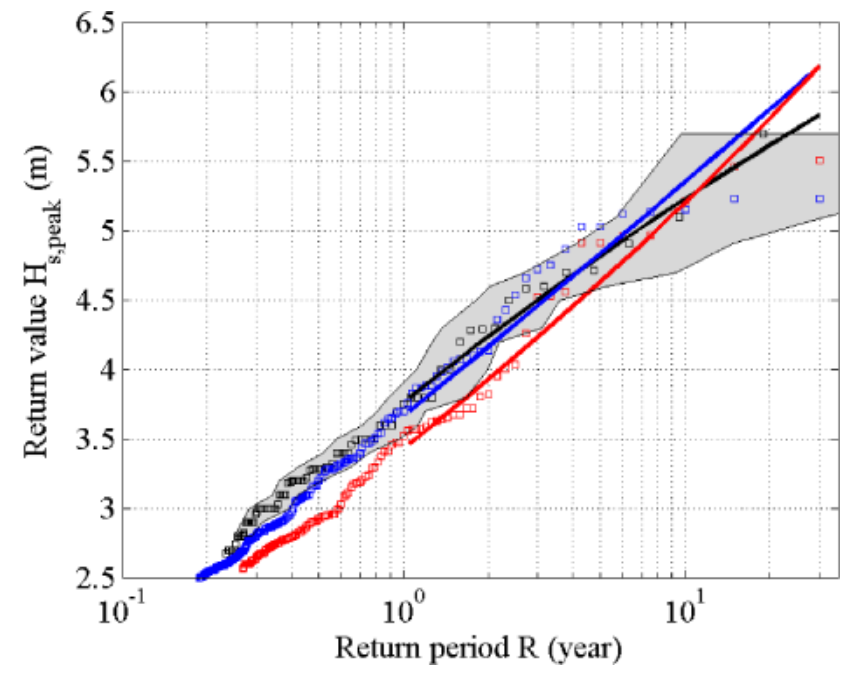

Fig. 4. Return level plot for $H_{\mathrm{s} \text {,peak }}$ at the Ortona buoy. Empirical data (squares) are the POT values for each dataset (black: observed; blue: CTR run; red: A1B run). The return period is calculated in accordance with Eq. (1), and the observed data confidence interval is bounded by the gray area. Empirical data are compared to the GPD results (solid lines in figure).

Table 1. Ortona and Monopoli goodness of fit. Obs: buoy data; CTR and A1B: modeled data. R-square: coefficient of determination; RMSE: root-mean-square error.

\begin{tabular}{lll}
\hline Parameter & GPD-Ortona & GPD-Monopoli \\
\hline R-square (Obs) & 0.99 & 0.99 \\
R-square (CTR) & 0.99 & 0.99 \\
R-square (A1B) & 0.99 & 0.99 \\
RMSE (Obs) & $0.06 \mathrm{~m}$ & $0.05 \mathrm{~m}$ \\
RMSE (CTR) & $0.04 \mathrm{~m}$ & $0.06 \mathrm{~m}$ \\
RMSE (A1B) & $0.04 \mathrm{~m}$ & $0.05 \mathrm{~cm}$ \\
\hline
\end{tabular}

The fitted distributions of CTR and A1B results show a reduction of the return values in the future, even if of secondary order with respect to the large uncertainty of the extreme events.

The diagnostic quantile plot (Fig. 5) is considered to estimate the goodness of the fit to the theoretical GPD. Two fitting parameters are calculated (see Table 1): the R-square error and the root-mean-square error (RMSE). The coefficient of determination (R-square) represents the correlation between data and fitted model, whereas RMSE accounts for the error in the regression. From Table 1, note that R-square values are close to 1 , meaning that GPD accounts for the data variance and nicely represents data, having differences in the order of $0.05 \mathrm{~m}$.

The statistics shown are based on the sea states described by the significant wave height $H_{\mathrm{s}}$. This represents the degree of sea severity, which relates to the expected maximum wave height $H_{\max }$ that can occur during a storm. In fact, for

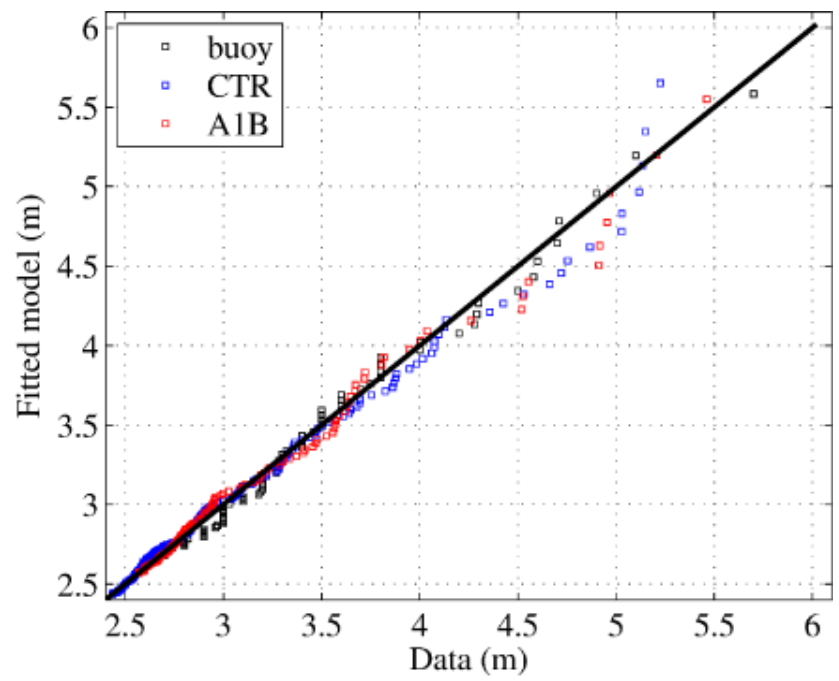

Fig. 5. Quantile plot of the GPD fit at the Ortona buoy. Black: observed; blue: CTR run; red: A1B run.

a given storm measured or modeled at a given point in space, $H_{\max }$ can be estimated ala "Borgman" using Eq. (4) and the Rayleigh law for the short-term wave statistics. For example, in the left panel of Fig. 6, we show a scatter plot displaying the $H_{\mathrm{s} \text {,peak }}$ value of the storm sequence and the associated expected values for $H_{\max }$. Buoy data show an average $H_{\text {max }} / H_{\text {s,peak }}$ ratio equal to 2.02 , while this ratio increases to 2.11 for both the CTR and A1B runs. These are typical values of sea surface waves, indicating their quasi-Gaussian statistical nature (see, for example, Boccotti, 2000; Fedele and Arena, 2010). The $H_{\text {max }} / H_{\text {s,peak }}$ ratio dependency on $H_{\max }$ is shown in the right panel of Fig. 6. As expected (Fedele and Arena, 2010), in Gaussian seas the ratio $H_{\text {max }} / H_{\text {s,peak }}$ reduces as $H_{\max }$ increases; so rare events have $H_{\max } / H_{\mathrm{s} \text {,peak }}$ smaller than that of more frequent typical events that can have $H_{\max } / H_{\mathrm{s} \text {,peak }}>2.00$. For example, in the observed data the maximum wave of a storm with a height $H_{\max }=8.00 \mathrm{~m}$ occurs in the strongest sea state of the storm with $H_{\text {s,peak }}$ $\approx H_{\max } / 2.04 \approx 3.92 \mathrm{~m}$. On the other hand, CTR results yield that the same wave height can occur in a sea state with slightly less strength, i.e. $H_{\text {s,peak }} \approx H_{\max } / 2.12 \approx 3.77 \mathrm{~m}$. This implies that CTR extremes are more frequent than those observed from buoy data.

This small difference can be explained by comparing the typical shape of wave storms in both the observed and modeled data. For example, Fig. 7 illustrates the $H_{\mathrm{s}}$ time sequence of storms computed by the SWAN model forced by the climatological wind (COSMO-CLM, dashed line) and by the wind provided by an operational meteorological model (COSMO-I7, dotted line). COSMO-I7 is the Italian version of the COSMO model, a mesoscale model developed in the framework of the COSMO Consortium (see www. cosmo-model.org). The typical storm shape is triangular (see, for example, Boccotti, 2000; Fedele and Arena, 2010), 

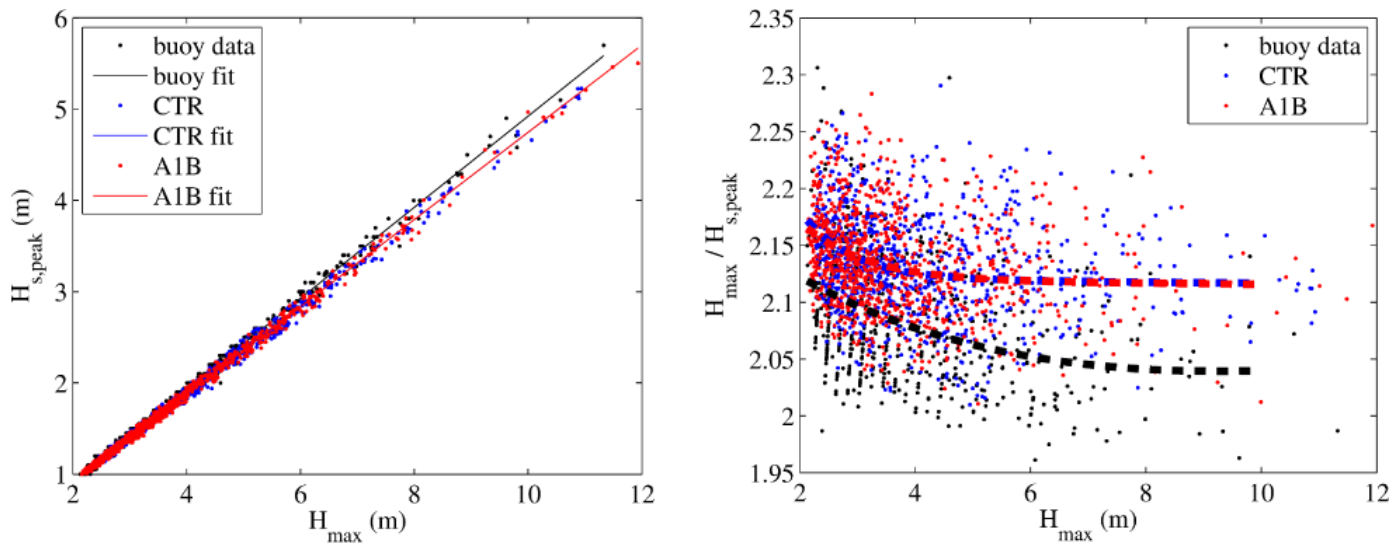

Fig. 6. Borgman's analysis of the storms at the Ortona buoy (black: observed; blue: CTR run; red: A1B run). Left: scatter plot of $\mathrm{H}_{\mathrm{max}}$ and $\mathrm{H}_{\mathrm{s} \text {,peak }}$ data. The linear fitting is superimposed to the collection of scattered points. Right: $\mathrm{H}_{\mathrm{max}} / \mathrm{H}_{\mathrm{s} \text {,peak }}$ ratio with respect to $\mathrm{H}_{\text {max }}$ for each storm. The exponential data fitting is superimposed (dashed line).

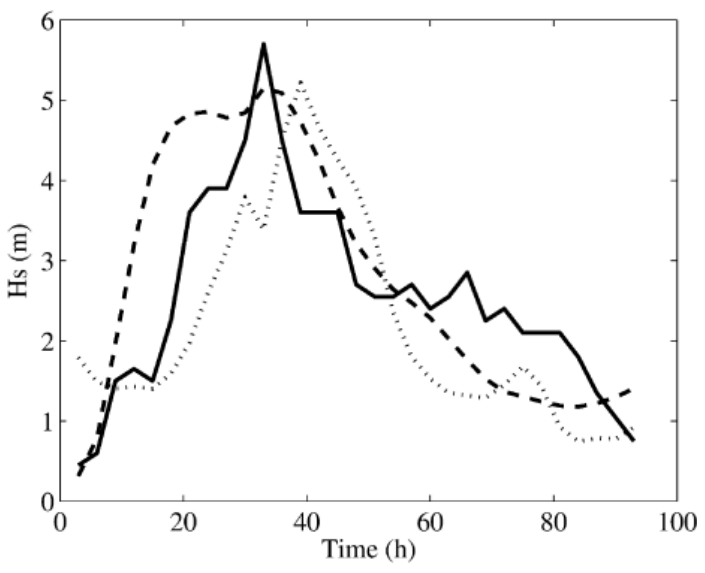

Fig. 7. A typical wave storm shape from the observed $H_{\mathrm{S}}$ data (solid line) and numerical simulations with two different wind forcings (dashed line: COSMO-CLM; dotted line: COSMO-I7).

as confirmed by buoy measurements (see solid line in Fig. 7) and by the wave field output produced by the operational meteorological model forcings. On the other hand, to the best of our knowledge, little attention has been devoted to investigate the storm shapes reproduced by climate models, which appear to be mostly parabolic, as clearly seen in Fig. 7. For given wave height, parabolic storms yield more intense extremes than triangular storms, viz. COSMO-CLM forcings can yield $H_{\max }$ value at moderate $H_{\mathrm{s} \text {,peak }}$ states, while buoy measurements indicate that to attain the same $H_{\max }$ requires stronger sea states. In this direction, the predictions of COSMO-CLM yield larger expected maximum wave heights, as depicted in Fig. 6, and modeled wave storms experience higher $H_{\mathrm{max}} / H_{\mathrm{s} \text {,peak }}$ ratios.

\section{Present and future wave climate of the Adriatic Sea}

In order to assess the wave severity in a climate change perspective, computed $H_{\mathrm{s}}$ are evaluated for the whole Adriatic Sea at all contiguous model grid locations. Even if Bora and Sirocco wind fields are distinct meteorological events, they are both closely related to cyclonic activity in the Mediterranean region (see Dorman et al., 2006 and references therein). Since the paper aims to quantify the expected future changes in the Adriatic Sea wave severity, the results are then presented showing the overall wave climate without distinctions between Bora and Sirocco episodes (projected Bora and Sirocco climate conditions can be found in Pasaric and Orlic, 2004).

Based on the wave data analyzed, the Adriatic Sea mean significant wave height is expected to decrease at a rate of about $0.05 \%$ per year, since 1965 . Indeed, the two $30-y r$ long periods analyzed are long enough to encompass the interannual climate modulations, and at the same time they still satisfy the hypothesis of stationarity of the wave climate (i.e., in $30 \mathrm{yr}$ the expected variation is about $1.5 \%$, less of other involved uncertainties).

Figures 8 and 9 show the average and the maximum significant wave heights $H_{\mathrm{S}}$ for the present climate (CTR run: 1965-1994 period) and for the future scenario (A1B run: 2070-2099 period). The CTR run presents higher values, but the difference with respect to the A1B run is small. The Adriatic Sea mean difference between A1B and CTR results is in the order of $5 \%$ and $6 \%$, for the average and maximum $H_{\mathrm{s}}$, respectively. In the future, highest reductions will be expected in the southern and northern Adriatic Sea, while simulations carried out show local increase of $H_{\mathrm{s}}$ levels in the central Adriatic Sea. An evaluation of the number of hours with significant wave height greater than two thresholds $(2 \mathrm{~m}$ and $5 \mathrm{~m}$ in Figs. 10 and 11, respectively) shows that this is 

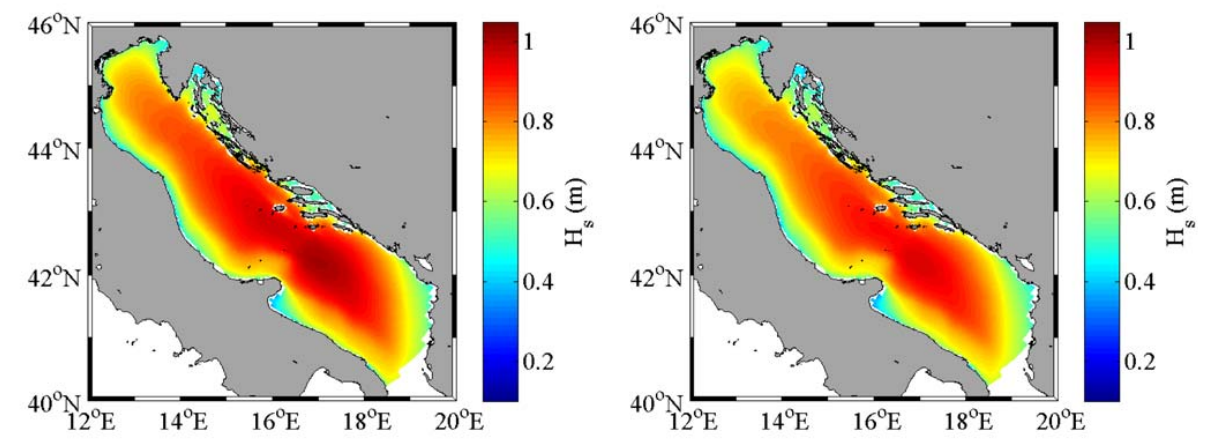

Fig. 8. Average $H_{\mathrm{s}}$ (in meters). Numerical simulations of the present climate (left) and the future scenario (right) are shown.
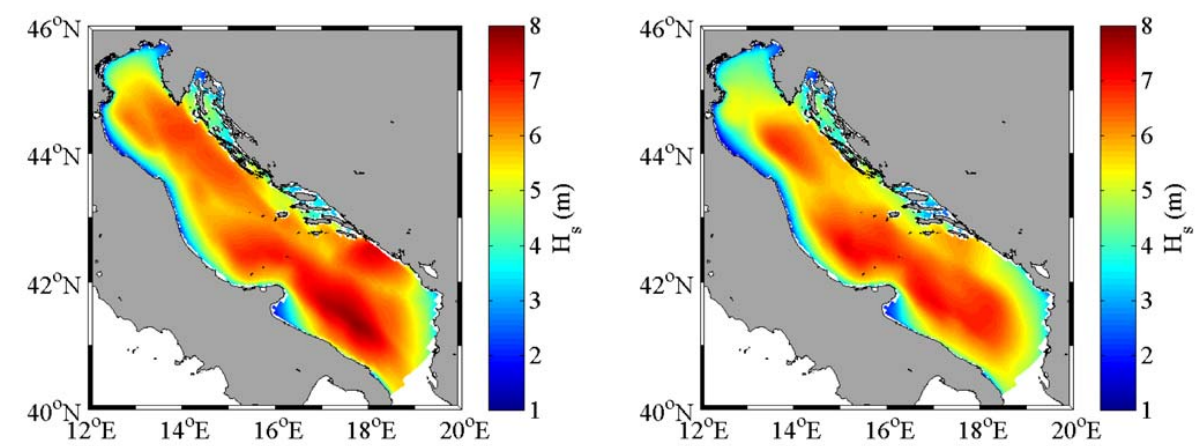

Fig. 9. Maximum $H_{\mathrm{s}}$ (in meters). Numerical simulations of the present climate (left) and the future scenario (right) are shown.
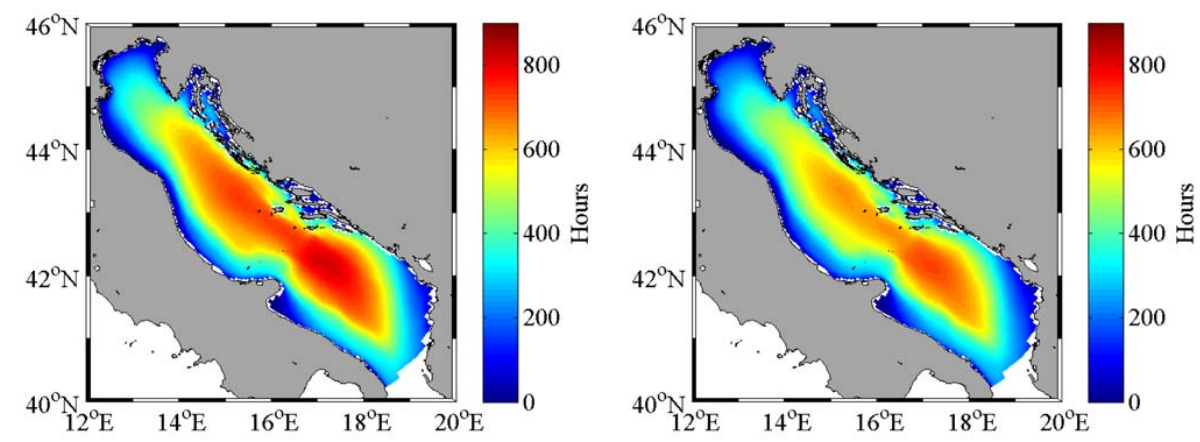

Fig. 10. Yearly average number of hours with $H_{\mathrm{S}}$ greater than $2 \mathrm{~m}$. Numerical simulations of the present climate (left) and the future scenario (right) are shown.
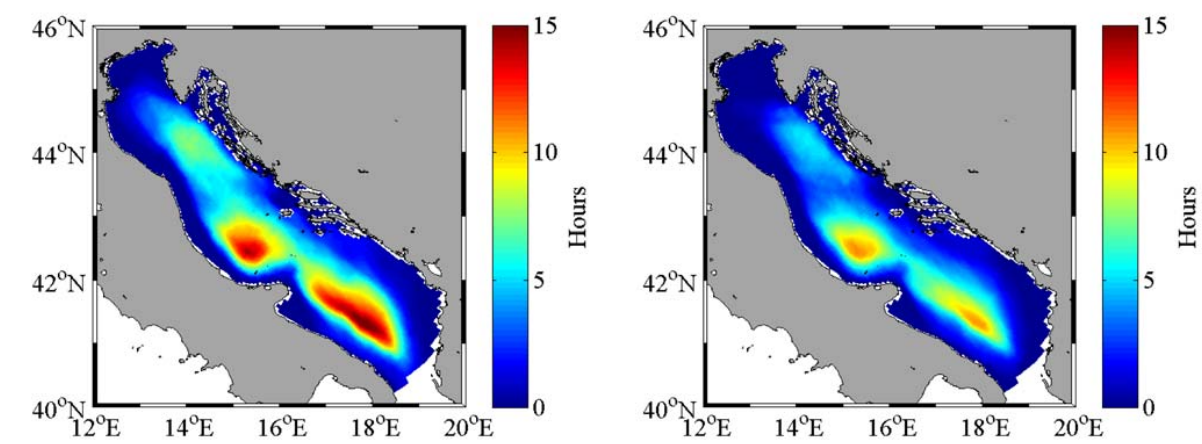

Fig. 11. Yearly average number of hours with $H_{\mathrm{S}}$ greater than $5 \mathrm{~m}$. Numerical simulations of the present climate (left) and the future scenario (right) are shown. 

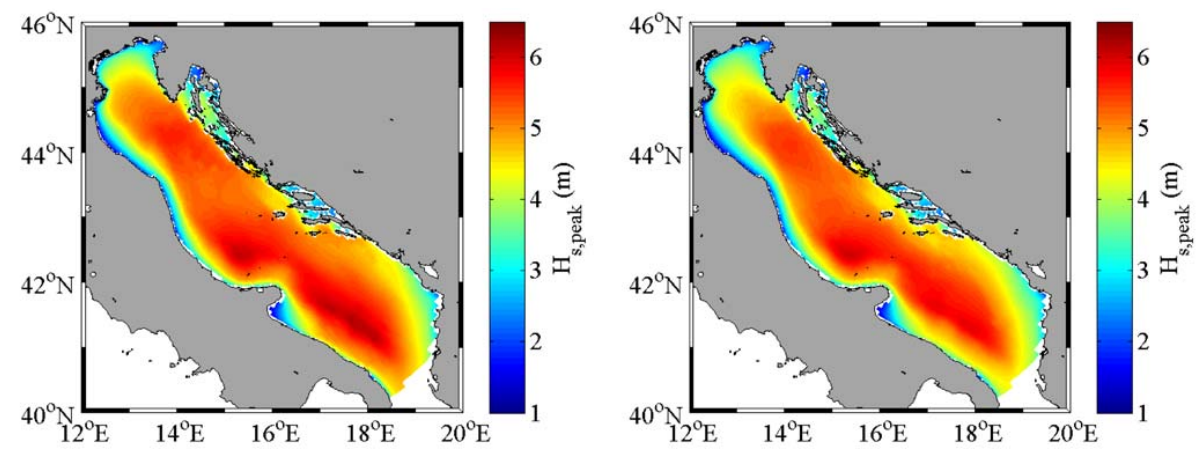

Fig. 12. 5-yr return significant wave height $H_{\mathrm{S}}$ (in meters). Numerical simulations of the present climate (left) and the future scenario (right) are shown.
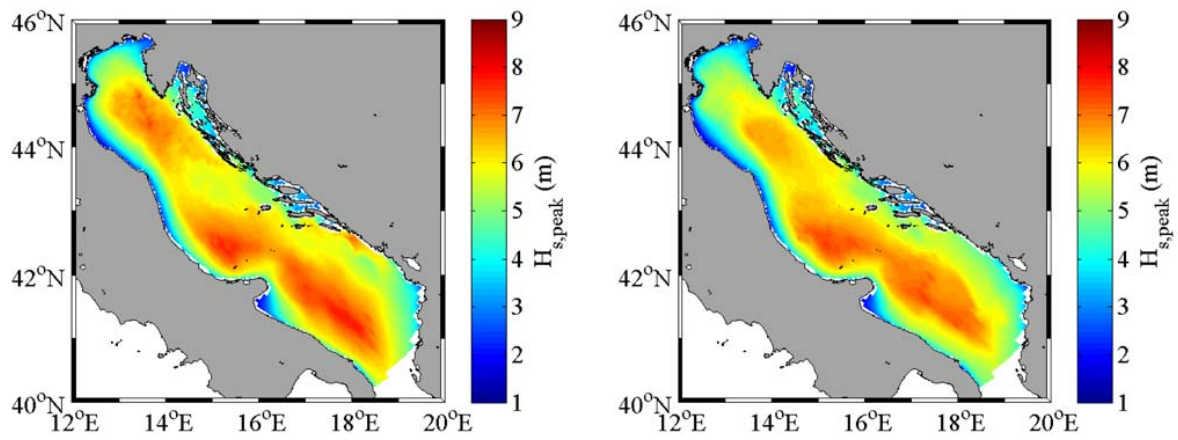

Fig. 13. 30-yr return significant wave height $H_{\mathrm{S}}$ (in meters). Numerical simulations of the present climate (left) and the future scenario (right) are shown.

generally smaller for the A1B run with respect to the present climate.

These conclusions are confirmed by the extreme value analysis applied to CTR and A1B datasets. The extreme wave analysis is based on the POT procedure applied to the two 30yr long simulated periods (CTR and A1B), fitting the $H_{\mathrm{s} \text {,peak }}$ values to a generalized Pareto distributions to obtain a return period curve. Figures 12 and 13 show the 5-yr (frequent event) and 30-yr (rare event) return value of the wave height $H_{\text {s,peak }}$, respectively. Note that the $30-y r$ return period significant wave height is the wave condition associated with the maximum time interval available in the two datasets CTR and A1B. These two sets of data are assumed to be representative of two stationary climatic conditions: the present and the expected future.

In accordance with the average wave conditions, the 30yr return $H_{\text {s,peak }}$ changes between A1B and CTR runs show milder waves for the future scenario, with an overall reduction of $5 \%$. Nevertheless, the simulations performed show a local increase of the $H_{\mathrm{s} \text {,peak }}$ of approximately $15 \%$ in the central and southern Adriatic Sea. Wave heights present lower values in the northern area, with expected reduction of

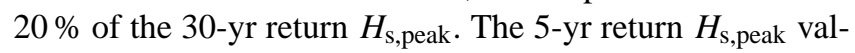
ues show a similar geographical pattern, even if the increase does not go over $3 \%$, and the reduction in the northern Adriatic is limited to $10 \%$.

Finally, the Borgman model of Eq. (4) permits to estimate the geographical pattern of the maximum expected wave height $H_{\max }$ for a 30-yr long period of sea states. Results for the present (CTR run) and future (A1B run) climates are shown in Fig. 14. In accordance with the pattern of maximum $H_{\mathrm{s}}$, Adriatic Sea maximum wave heights are located in the southern Adriatic Sea for both runs. The predicted future changes are small, in the order of $5 \%$, leaving unchanged the probability of single waves higher than $10 \mathrm{~m}$ for most of the Adriatic Sea. The Adriatic Sea future mean ratio $H_{\max } / H_{\mathrm{s} \text {,peak }}$ is expected to remain equal to the estimated actual value of 2.06 .

\section{Summary and conclusions}

The main objective of this study was to assess a possible future changes in the estimate of the average and extreme sea wave states over Adriatic Sea. The procedure was applied to two 30-yr long periods of wave fields generated by winds simulated by the climatological model COSMO-CLM at 14$\mathrm{km}$ horizontal resolution. In the Adriatic Sea region, which is characterized by a complex orography, this resolution was shown to adequately reproduce small spatial scale patterns, 

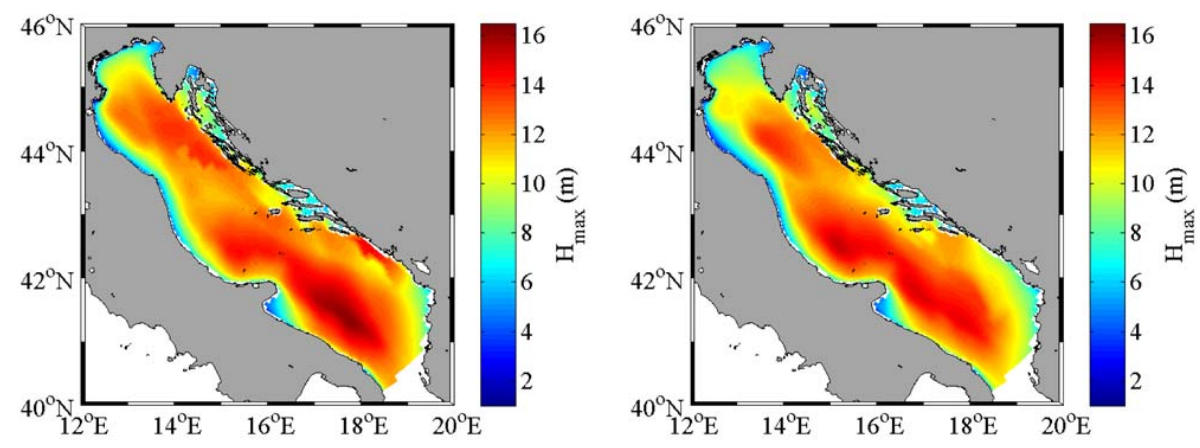

Fig. 14. Borgman's analysis: Largest expected maximum wave height $H_{\max }$ in a storm (in meters). Numerical simulations of the present climate (left) and the future scenario (right) are shown.

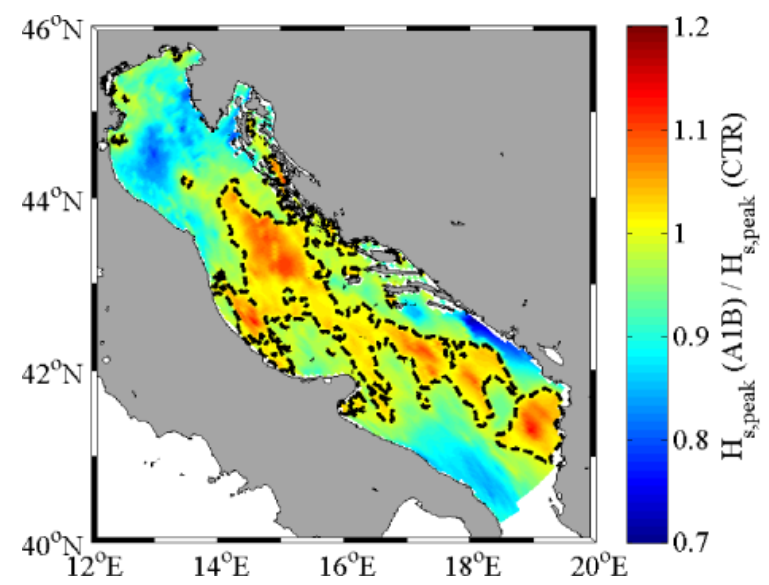

Fig. 15. 30-yr return period $H_{\mathrm{s} \text {,peak }}$ based on the GPD. Pattern of the $H_{\mathrm{s} \text {,peak }}$ ratio between A1B and CTR results. The black dashed line shows the isoline 1.0.

albeit using wind products from NWP systems (Signell et al., 2005). This approach allowed to provide a high-resolution mapping of the whole Adriatic Sea, in comparison with previous studies that were employing wind fields at about $50 \mathrm{~km}$ resolution (Lionello et al., 2008, 2012).

The two periods were analyzed for the simulated wind conditions of the present-day (CTR run: 1965-1994) and the predicted (A1B run: 2070-2099) climate conditions, based on the IPCC A1B emission scenario, which is considered a balance of all energy sources (IPCC, 2007) and is a mid line between A2 medium-high emission and B2 medium-low emission scenarios. The wave simulations were performed with the SWAN model on the whole Adriatic Sea, implemented with a grid resolution of approximately $8 \mathrm{~km}$. The results are two 30-yr long time series of significant wave heights $H_{\mathrm{s}}$ for every computational cell, which has shown an overall trend similar results with respect to Lionello et al. (2012) in the northern Adriatic sea, where a reduction of extreme wave events was envisaged in the future scenario with respect to the present-day situation.
The comparison between the CTR run results and available field data showed that the modeled wave fields reproduce to a good extent the seasonality of Adriatic Sea wave climate, as well as the long-term statistics of wave extremes. Noteworthy, the wave storms resulting from the COSMOCLM model show a parabolic shape instead of the typical triangular form observed from measurements and reported in literature (see, for example, Boccotti, 2000; Fedele and Arena, 2010). This produces small differences in the individual maxima wave height, here investigated by means of Borgman's theory, applied to both modeled and measured data. Nevertheless, Borgman's analysis showed that the future storm shape will remain unchanged, i.e. there is no tendency of more intense short-duration wave storm events.

Some statistical parameters were calculated to estimate the differences between the current and the future wave climate simulations. Our analysis shows that, relative to the present level, global Adriatic Sea wave severity is likely to decrease by $5 \%$ by the end of the 21 th century. In particular, following the generalized Pareto distribution, the mean Adriatic Sea 30yr return significant wave height would decrease by $0.28 \mathrm{~m}$ between 1990s and the 2090s, with a maximum decrease of $2.13 \mathrm{~m}$ and a maximum increase of $0.85 \mathrm{~m}$.

As expected, the wave height variations will not occur uniformly across the Adriatic, with some regions experiencing higher levels of waves and others lower (see for example Fig. 15). Such variations are due to the variations in the local wind climate, in accordance with expected changes of the two dominant winds in the Adriatic Sea, Bora and Sirocco. Further studies, though, are required to distinguish the Bora and Sirocco roles to produce the local wave climate.

Based on the data herein analyzed, useful suggestions can be forwarded about the future Adriatic Sea wave climate. When evaluating the impact of climate change on the design of new marine structures and on the safety of existing ones, the design wave based on past events seems to lead to conservative conditions for a future scenario. The differences, however, between the present and the future wave climate are 
small and comparable with the uncertainty that is associated with extreme events.

As a final recommendation, it should be noted that when dealing with climate change-related issues, improvements of the reliability level of design should require a statistical analysis for extremes that accounts for non-stationary conditions.

Acknowledgements. The Authors gratefully acknowledge the funding from the EC FP7/2007-2013 under grant agreement no. 242284 (Project "FIELD_AC"). The work was also partially supported by the FIRB RBFR08D825_001 grant (Project “DECALOGO”).

Edited by: U. Ulbrich

Reviewed by: V. Alari, J. Dykes, and another anonymous referee

\section{References}

Bellafiore, D., Bucchignani, E., Gualdi, S., Carniel, S., Djurdjevic, V., and Umgiesser, G.: Assessment of meteorological climate models as inputs for coastal studies, Ocean Dynam., 62, 555568, 2012.

Bignami, F., Sciarra, R., Carniel, S., and Santoleri, R.: Variability of Adriatic Sea coastal turbid waters from SeaWiFS imagery, J. Geophys. Res., 112, C03S10, doi:10.1029/2006JC003518, 2007.

Bitner-Gregersen, E. M. and Eide, L. I.: DNV Position Paper No.8 "Potential Impact of Climate Change on Tanker Design", 1-20, 2011.

Boccotti, P.: Wave Mechanics for Ocean Engineering, Elsevier Science, Oxford, 496 pp., 2000.

Booij, N., Ris, R., and Holthuijsen, L.: A third-generation wave model for coastal regions 1 . Model description and validation, J. Geophys. Res., 104, 7649-7666, 1999.

Boldrin, A., Carniel, S., Giani, M., Marini, M., Bernardi Aubry, F., Campanelli A., Grilli, F., and Russo A.: The effect of Bora wind on physical and bio-chemical properties of stratified waters in the northern Adriatic, J. Geophys. Res.-Ocean, 114, C08S92, doi:10.1029/2008JC004837, 2009.

Borgman, L. E.: Probabilities for the highest wave in a hurricane, J. Waterway, Port, Coast. Ocean Eng., 99, 185-207, 1973.

Brodtkorb, P. A., Johannesson, P., Lindgren, G., Rychlik, I., Rydén, J., and Sjö, E.: WAFO - a Matlab toolbox for analysis of random waves and loads, Proceedings of the 10th International Offshore and Polar Engineering conference, Seattle, III, 343-350, 2000.

Bucchignani, E., Sanna, A., Gualdi, S., Castellari, S., and Schiano, P.: Simulation of the climate of the $\mathrm{XX}$ century in the Alpine space, Nat. Hazards, in press, http://www.springerlink.com/content/c1710wp74r75677n/, doi:10.1007/s11069-011-9883-8, 2011.

Carniel, S., Warner, J. C., Chiggiato, J., and Sclavo, M.: Investigating the impact of surface wave breaking on modelling the trajectories of drifters in the northern Adriatic Sea during a wind-storm event, Ocean Model., 30, 225-239, 2009.

Carniel, S., Sclavo, M., and Archetti, R.: Towards validating a last generation, integrated wave-current-sediment numerical model in coastal regions using video measurements, Oceanol. Hydrobiol. Stud., 40, 11-20, 2011.

Coles, S.: An Introduction to Statistical Modeling of Extreme Values, Springer-Verlag, London, 228 pp., 2001.
Dorman, C. E., Carniel, S., Cavaleri, L., Sclavo, M., Chiggiato J., and others: February 2003 marine atmospheric conditions and the Bora over the northern Adriatic, J. Geophys. Res.-Ocean, 111, C03S03, doi:10.1029/2005JC003134, 2006.

Dykes, J. D., Wang, D. W., and Book, J. W.: An evaluation of a highresolution operational wave forecasting system in the Adriatic Sea, J. Mar. Syst., 78, 255-271, 2006.

Fedele, F.: Space-time extremes of short-crested storm seas, J. Phys. Oceanogr., in press, 2012.

Fedele, F. and Arena, F.: Long-term statistics and extreme waves of sea storms, J. Phys. Oceanogr., 40, 1106-1117, 2010.

Forristall, G. Z.: How should we combine long and short term wave height distributions?, Proceedings of the OMAE08 27th International Conference on Offshore Mechanics and Arctic Engineering June 15-20, Estoril, Portugal, 2008.

Intergovernmental Panel on Climate Change (IPCC): in: Emissions Scenarios: Special Report of the Intergovernmental Panel on Climate Change, edited by: Nakicenovic, N. and Swart, R., Cambridge University Press, 570 pp., 2000.

Intergovernmental Panel on Climate Change (IPCC): Fourth Assessment Report. Intergovernmental Panel on Climate Change Secretariat, Geneva, Switzerland, 2007.

Lionello, P., Elvini, E., and Nizzero, A.: Ocean waves and storm surges in the Adriatic Sea: intercomparison between the present and doubled $\mathrm{CO}_{2}$ climate scenarios, Clim. Res., 23, 217-231, 2003.

Lionello, P., Cogo, S., Galati, M. B., and Sanna, A.: The Mediterranean surface wave climate inferred from future scenario simulations, Global Planet. Change 63, 152-162, 2008.

Lionello, P., Galati, M. B., and Elvini, E.: Extreme storm surge and wind wave climate scenario simulations at the Venetian littoral, Phys. Chem. Earth, Parts A/B/C, 40-41, 86-92, 2012.

Martucci, G., Carniel, S., Chiggiato, J., Sclavo, M., Lionello, P., and Galati, M. B.: Statistical trend analysis and extreme distribution of significant wave height from 1958 to 1999 - an application to the Italian Seas, Ocean Sci., 6, 525-538, doi:10.5194/os-6-5252010, 2010.

May, W. and Roeckner, E.: A time-slice experiment with the ECHAM4 AGCM at high resolution: the impact of horizontal resolution on annual mean climate change, Clim. Dynam., 17, 407-420, 2001.

Pal, J. S., Small, E. E., and Eltahir, E. A. B.: Simulation of regionalscale water and energy budgets: Representation of subgrid cloud and precipitation processes within RegCM, J. Geophys. Res.Atmos., 105, 29579-29594, 2000.

Pasaric, M. and Orlic, M.,: Meteorological forcing of the Adriatic - present vs. projected climate conditions, Geofizika, 21, 69-87, 2004.

Prevosto, M., Krogstad, H. E., and Robin, A.: Probability distributions for maximum wave and crest heights, Coast. Eng., 40, 329-360, 2000.

Raisanen, J., Hansson, U., Ullerstig, A., Doscher, R., Graham, L. P., Jones, C., Meier, H. E. M, Samuelsson, P., and Willen, U.: European climate in the late twenty-first century: regional simulations with two driving global models and two forcing scenarios, Clim. Dynam., 22, 13-31, 2004.

Rockel, B. and Woth, K.: Extremes of near-surface wind speed over Europe and their future changes as estimated from an ensemble of RCM simulations, Climatic Change, 81, 267-280, 2007. 
Rockel, B., Will, A., and Hense, A.: The regional Climate Model COSMO-CLM (CCLM), Meteorol. Z., 17, 347-348, 2008.

Sclavo, M., Liberatore, G., and Ridolfo, R.: Waves in front of the Venetian littoral, Il Nuovo Cimento, 19, 125-150, 1996.

Shao, Y. and Hahn, M. G.: Maximum product of spacings method: A unified formulation with illustration of strong consistency, Illinois J. Math., 43, 489-499, 1999.

Signell, R. P., Carniel, S., Cavaleri, L., Chiggiato, J., Doyle, J., Pullen, J., and Sclavo, M.: Assessment of wind quality for oceanographic modeling in semi-enclosed basins, J. Mar. Syst., 53, 217-233, 2005.
Steppeler, J., Doms, G., Schättler, U., Bitzer, H. W., Gassmann, A., Damrath, U., and Gregoric, G.: Meso-gamma scale forecasts using nonhydrostatic model LM, Meteorol. Atmos. Phys., 82, 7596, 2003.

Tayfun, M. A. and Fedele, F.: Wave-height distributions and nonlinear effects, Ocean Engineering, 34, 1631-1649, 2007.

Vinoth, J. and Young, I. R.: Global estimates of extreme wind speed and wave height, J. Climate, 24, 1647-1665, 2011.

WMO (World Meteorological Organization): Guide to Wave Analysis and Forecasting, second edition, 159 pp., 1998. 